\title{
Características das fibras musculares de cordeiros nascidos de ovelhas recebendo suplementação proteica no terço inicial da gestação
}

\section{Graziela Aparecida Santello ${ }^{1}$, Francisco de Assis Fonseca de Macedo ${ }^{2}$, Rosa Maria Gomes de Macedo $^{2}$, Elias Nunes Martins ${ }^{2}$, Fábio José Lourenço ${ }^{3}$, Fábio Jacobs Dias ${ }^{3}$}

\footnotetext{
${ }^{1}$ Departamento de Zootecnia da Universidade Federal do Amazonas - UFAM.

2 Departamento de Zootecnia da UEM - Campus Universitário - Av. Colombo, 5790 - CEP: 87020-900 - Maringá, PR.

${ }^{3}$ Doutorando do Departamento de Zootecnia da Universidade Estadual de Maringá, PR, Brasil.
}

RESUMO - Foram utilizadas 80 ovelhas Santa Inês, com 47,49 $\pm 3,76 \mathrm{~kg}$ de peso vivo, cobertas com reprodutores Dorper e alimentadas com concentrado com 15,20;22,48; 26,52 e 35,65\% de proteína bruta (PB) no terço inicial de gestação. As ovelhas, durante o dia, permaneceram em pastagem de capim-aruana (Panicum maximum cv. Aruana). Ao nascimento, foram realizadas biópsias no músculo Semitendinosus esquerdo de cordeiros machos, para avaliar o número e o diâmetro das fibras musculares. Na fase de terminação, os cordeiros foram distribuídos em dois grupos e alimentados com uma dieta controle, contendo $16,18 \%$ de proteína bruta (PB) e 79,64\% nutrientes digestíveis totais (NDT), sem grão de girassol; ou com uma dieta contendo $9,10 \%$ de grãos de girassol $(15,03 \%$ de PB e $78,96 \%$ de NDT). Não houve efeito da alimentação materna sobre o peso dos cordeiros ao nascimento $(4,82 \mathrm{~kg})$, aos 30 dias de idade $(9,69 \mathrm{~kg})$ e ao desmame $(15,38 \mathrm{~kg})$. O sexo influenciou o peso dos cordeiros ao nascimento e ao desmame. O desempenho dos cordeiros na fase de terminação não foi influenciado pela dieta fornecida nessa fase, nem pelo sexo nem pelo manejo alimentar da mãe durante a gestação. Não houve diferença no número $(2813,45)$ nem no diâmetro $(13,16 \mu \mathrm{m})$ das fibras musculares ao nascimento. $\mathrm{O}$ teor de PB de dietas para ovelhas no terço inicial da gestação pode ser reduzido, pois essa redução não influencia no diâmetro e número de fibras musculares.

Palavras-chave: desenvolvimento ponderal, ovinos, tratamento materno

\section{Characteristics of muscle fibers of lambs born from sheep given protein suplementation in the intial third of pregnancy}

\begin{abstract}
It was used 80 Santa Inês ewes with average body weight $47.79 \pm 3.76 \mathrm{~kg}$, mated with Dorper rams and fed concentrated diet with $15.20 ; 22.48 ; 26.52$ and $35.65 \%$ crude protein $(\mathrm{CP})$ on the initial third of pregnancy. Sheep were kept on aruana grass (Panicum maximum cv. Aruana) pasture during the day. At birth, biopsy on the left Semitendinosus muscle were done on male lambs to evaluate the number and diameter of muscular fibers. During finishing phase, lambs were distributed in two groups and fed control diet with $16.18 \%$ crude protein (CP) and $79.64 \%$ total digestible nutrients (TDN); without sunflower grain; or fed diet with $9.10 \%$ sunflower grain $(15.03 \% \mathrm{CP}$ and $78.96 \% \mathrm{TDN})$. There was no effect of maternal feeding on the weight of lambs at birth $(4.82 \mathrm{~kg})$, at 30 days of age $(9.69 \mathrm{~kg})$ and at weaning $(15.38 \mathrm{~kg})$. Sex affected weight of lambs from birth to weaning. Performance of the lambs during finishing phase was not affected by diet given during this phase, neither by the sex nor by maternal food management during pregnancy. There was no difference on number $(2,813.45)$ neither on diameter $(13.16 \mu \mathrm{m})$ of the muscle fibers on birth. Contents of crude proteins in diets for sheep at the initial third of pregnancy can be reduced because this reduction does not affect diameter and number of muscle fibers
\end{abstract}

Key Words: maternal treatment, sheep, weight development

\section{Introdução}

A criação de ovinos determina grande parte da produção pecuária e desempenha papel produtivo nas mais diversas regiões do mundo. O consumo de carne ovina foi estimado em 13,8 milhões de toneladas em 2007, um aumento de 3,6\% em relação ao ano de 2006, enquanto, no Brasil, tem sido estimado em $0,700 \mathrm{~kg} /$ pessoa/ano (FAO, 2007).
O cordeiro é potencialmente a categoria da espécie ovina com carne de maior aceitabilidade no mercado, melhores características de carcaça e menor ciclo de produção (Figueiró \& Benavides, 1990).

O crescimento muscular está associado ao aumento do diâmetro das fibras, que, segundo Greenwood et al. (2000), é influenciado pelo nível nutricional da dieta das mães. Há controvérsias quanto à época de formação das fibras 
musculares esqueléticas em ovinos. Wilson et al. (1992) descreveram a presença de miotubos primários aos 32 dias de gestação, com número máximo atingido aos 38 dias de desenvolvimento fetal, quando se observam os primeiros miotubos secundários. De acordo com alguns autores (Swatland \& Cassens 1973; Maier et al., 1992), a miogênese é completada entre 80 e 125 dias de gestação, enquanto a formação dos músculos completa-se aos 140 dias de gestação (Finkelstein et al., 1992). No entanto, Greenwood et al. (1998) relataram que o número de fibras musculares estabiliza-se aos 100 dias de gestação e que, a partir dessa fase, o suprimento de nutrientes ao feto torna-se determinante do crescimento de ovinos.

A nutrição inadequada da ovelha durante a gestação pode limitar a capacidade de crescimento pós-natal dos músculos esqueléticos de cordeiros (Greenwood et al., 2000), uma vez que não ocorre hiperplasia muscular em mamíferos após o nascimento. Nutrição pré-natal adequada contribui para que haja hipertrofia das fibras primárias, o que resulta em hiperplasia das fibras secundárias, pois as primárias servem como apoio para as secundárias (Wilson et al., 1992). O número de fibras musculares ao nascimento em animais pode proporcionar maior velocidade de ganho de peso pósparto.

Desse modo, o objetivo neste trabalho foi avaliar o desenvolvimento ponderal de cordeiros $1 / 2$ Dorper - Santa Inês machos e fêmeas do nascimento à terminação e o diâmetro e número de fibras musculares do músculo semitendinosus dos cordeiros machos ao nascimento, provenientes de ovelhas submetidas a dietas com diferentes teores de proteína bruta no terço inicial de gestação.

\section{Material e Métodos}

O experimento foi realizado no Centro de Pesquisa do Arenito, da Universidade Estadual de Maringá (UEM), no município de Cidade Gaúcha, noroeste do Paraná no período de março de 2006 a fevereiro de 2007.

Foram selecionadas 80 ovelhas da raça Santa Inês, com $47,79 \pm 3,76 \mathrm{~kg}$ de peso vivo (PV) e 3 a 4 anos de idade e utilizados dois reprodutores da raça Dorper em monta natural assistida. O cio das ovelhas foi detectado com a utilização de dois rufiões, e as ovelhas que apresentavam cio foram cobertas duas vezes em intervalo de 12 horas.

Durante o experimento, as ovelhas permaneceram em pastagem de capim-aruana (Panicum maximum cv. Aruana) no período diurno e foram recolhidas em instalações cobertas, com piso ripado e suspenso, às $16 \mathrm{~h}$. No terço inicial da gestação, quando ocorre a formação das fibras musculares esqueléticas em ovinos, foram utilizadas quatro dietas, formuladas para atender 80,100, 120 e $140 \%$ das exigências em proteína bruta, conforme descrito a seguir: pastagem de capim-aruana + suplemento com $15,20 \%$ de PB; pastagem de capim-aruana + suplemento com $22,48 \%$ de PB (controle); pastagem de capim-aruana + suplemento com $26,52 \%$ de PB; pastagem de capim-aruana + suplemento com $35,65 \%$ de PB.

Os suplementos (Tabela 1) foram calculados de acordo com as exigências, um com nível abaixo e dois com níveis superiores às exigências nutricionais das ovelhas na fase de inicial de gestação (NRC, 1985), que são de 10,6\% de PB, $59 \%$ de nutrientes digestíveis totais (NDT) e 3\% de ingestão de matéria seca.

Tabela 1 - Composição percentual e teores dos concentrados, com base na matéria seca

\begin{tabular}{|c|c|c|c|c|}
\hline \multirow[t]{2}{*}{ Ingrediente $(\%)$} & \multicolumn{4}{|c|}{ Composição percentual } \\
\hline & $15,20 \% \mathrm{~PB}$ & $22,48 \%$ PB & $26,52 \% \mathrm{~PB}$ & $35,65 \% \mathrm{~PB}$ \\
\hline Milho moído & 85,20 & 71,00 & 57,00 & 54,00 \\
\hline Ureia $(\%)$ & - & 0,50 & 1,00 & 1,50 \\
\hline \multirow[t]{2}{*}{ Mineral (\%) } & 2,00 & 2,00 & 2,00 & 2,00 \\
\hline & \multicolumn{4}{|c|}{ Composição química (\%/MS) } \\
\hline Fibra em detergente neutro (\%) & 17,08 & 14,98 & 12,17 & 14,99 \\
\hline Fibra em detergente ácido (\%) & 5,34 & 5,67 & 5,75 & 7,73 \\
\hline Nutrientes digestíveis totais ${ }^{1}(\%)$ & 84,10 & 83,87 & 83,81 & 82,42 \\
\hline Extrato etéreo $(\%)$ & 3,39 & 3,38 & 4,13 & 4,13 \\
\hline Matéria mineral (\%) & 4,09 & 4,10 & 5,64 & 5,64 \\
\hline
\end{tabular}

${ }^{1}$ NDT do concentrado estimado pela equação (Undersander et al., 1993): \%NDT $=87,84-(0,70 \times$ FDA). 
Foi avaliada a disponibilidade de matéria seca e analisada a composição química do capim-aruana, obtida pelo corte da planta a $5 \mathrm{~cm}$ do solo, utilizando-se um quadrado de $25 \mathrm{~cm}^{2}$, sendo efetuados quatro cortes. A estimativa da massa de forragem na pastagem foi realizada pelo método da dupla amostragem (Wilm et al., 1944). A disponibilidade da forragem foi de $1.847 \mathrm{~kg} \mathrm{MS} / \mathrm{ha}$, a área disponível para o experimento foi de 3 ha e o teor de $\mathrm{PB}$ $6,2 \%$, de fibra em detergente neutro (FDN) de 55,43\% e $95,5 \%$ de MS.

O suplemento foi fornecido para as ovelhas no terço inicial de gestação somente no período da tarde, depois dos animais retornarem da pastagem, na quantidade de $0,450 \mathrm{~kg} / \mathrm{MS} / \mathrm{dia}$.

Os minerais foram misturados ao concentrado de cada dieta. As ovelhas receberam as dietas do primeiro dia da cobertura até o $50^{\circ}$ dia de gestação e, no terço médio e final da gestação, receberam suplemento para suprir as exigências de cada fase da gestação (NRC, 1985).

A infecção por endoparasitas foi acompanhada mensalmente por meio da contagem de ovos por grama de fezes (OPG), e as ovelhas everminadas quando a contagem foi superior a 1000 OPG (Lourenço, 2006). Aos 30 dias antes do parto, as ovelhas foram vacinadas contra clostridioses.

O nascimento dos cordeiros ocorreu no período de setembro a outubro de 2006. Na primeira semana de vida, as ovelhas e os cordeiros ficaram alojados nas instalações. $\mathrm{Na}$ segunda e terceira semanas, as ovelhas tiveram acesso aos piquetes por quatro horas e, da quarta semana até o desmame, permaneceram nos piquetes por oito horas. Todos os cordeiros do nascimento até a entrada no sistema de terminação receberam o mesmo manejo, com acesso ao creep feeding e dieta formulada para ganho médio de 230 gramas/dia (NRC, 1985). A ração do creep feeding foi formulada para conter $20 \%$ de PB, 3,0 Mcal de EM $/ \mathrm{kg}$ de MS, 1,46\% de cálcio e 1,0\% de fósforo e foi constituída de $55 \%$ de milho moído; $24 \%$ de farelo de soja; $9 \%$ de farelo de trigo; $10 \%$ de feno de aveia; $2 \%$ de mistura mineral comercial; $0,2 \%$ lisina e $0,08 \%$ de metionina.

Após o nascimento, aos 3 dias de idade, foram coletadas por biopsia amostras da região superficial mediana do músculo semitendinosus esquerdo de oito cordeiros para cada nível de suplementação proteica, totalizando 32 cordeiros machos nascidos de parto simples ou duplo, para mensuração do diâmetro e contagem do número das fibras.

Os cordeiros foram vacinados aos 15 dias de idade contra ectima contagioso e aos 45 dias de idade, contra carbúnculo, gangrena gasosa e enterotoxemia. Os cordeiros machos e fêmeas foram identificados e posteriormente pesados ao nascimento, aos 30 dias e ao desmame (58 dias de idade em média).
Após o desmame, aproximadamente 58 dias de idade, 28 machos (12 nascidos de parto duplo e 16 nascidos de parto simples) e 27 fêmeas (13 nascidos de parto duplo e 14 nascidos de parto simples), obedecendo ao tratamento materno, ao tipo de parto e ao sexo, foram distribuídos em duas dietas (sem e com grãos de girassol) e terminados em confinamento. Os cordeiros foram alojados em baias coletivas, cobertas e com piso ripado suspenso, onde receberam água à vontade durante todo o período experimental. Os animais foram pesados no início do experimento e a cada 14 dias.

As rações peletizadas (Tabela 2) foram fornecidas duas vezes ao dia, à vontade, de modo a proporcionar sobras diárias de aproximadamente $10 \%$. As amostras do músculo semitendinosus após coleta foram mantidas à temperatura ambiente durante 15 minutos (Khan, 1977), sendo aparadas e reduzidas a fragmentos de $1,0 \times 0,5 \mathrm{~cm}$, envoltas em talco branco e congeladas em nitrogênio líquido. As amostras congeladas foram armazenadas em freezer a $-80^{\circ} \mathrm{C}$ até o processamento.

Amostras do músculo semitendinosus coletadas ao nascimento foram transferidas para a câmara de micrótomo criostato TISSUE - TEK II, com temperatura interna de $-20^{\circ} \mathrm{C}$, e permaneceram neste ambiente por uma hora. Posteriormente, cada amostra foi afixada em suporte metálico com adesivo especial "Tissue Tek OCT (Optimal Cristal Temperature)" e submetida a vários cortes histológicos com $10 \mu \mathrm{m}$ de espessura e colhidos em lâminas (Pullen, 1977). As séries de cortes com $10 \mu \mathrm{m}$ de espessura foram submetidas à coloração pela técnica denominada

Tabela 2 - Composição da ração dos cordeiros na fase de terminação

\begin{tabular}{lcc}
\hline Ingrediente & Dieta de terminação \\
\cline { 2 - 3 } & Controle (\%) & $\begin{array}{c}\text { Grãos de } \\
\text { girassol (\%) }\end{array}$ \\
\hline Feno de aveia & 23,96 & 21,05 \\
Milho moído & 54,28 & 50,77 \\
Farelo de soja & 19,20 & 16,49 \\
Grãos girassol & - & 9,10 \\
Minerais & 1,71 & 1,71 \\
Sal comum & 0,50 & 0,50 \\
Calcário & 0,85 & 0,85 \\
Monensina sódica & 0,01 & 0,01 \\
Composição química (\%) & & \\
Matéria seca (MS) & 89,41 & 90,26 \\
Proteína bruta (PB) & 16,18 & 15,03 \\
Fibra em detergente neutro (FDN) & 24,41 & 22,98 \\
Fibra em detergente ácido (FDA) & 11,71 & 12,68 \\
Nutrientes digestíveis totais (NDT) & 79,64 & 78,96 \\
Extrato etéreo (EE) & 2,89 & 4,87 \\
Material mineral (MM) & 6,49 & 5,63 \\
\hline 1 NDTconcentrado estimada pela equação (Undersander et & al., 1993$)$ : \\
\%NDT = 87,84-(0,70 x FA). & &
\end{tabular}


hematoxilina e eosina (HE) (Lillie, 1954), para avaliação da morfologia geral do tecido, contagem e mensurações das fibras.

De acordo com as características morfológicas, as fibras apresentaram forma arredondada, são polinucleadas, e organizadas em padrão fascicular bem definido. O tecido conjuntivo que envolve cada uma das fibras é pouco desenvolvido (muitas vezes só se identifica o espaço originado pela retração do endomísio), conferindo aspecto compacto às fibras (Figura 1).

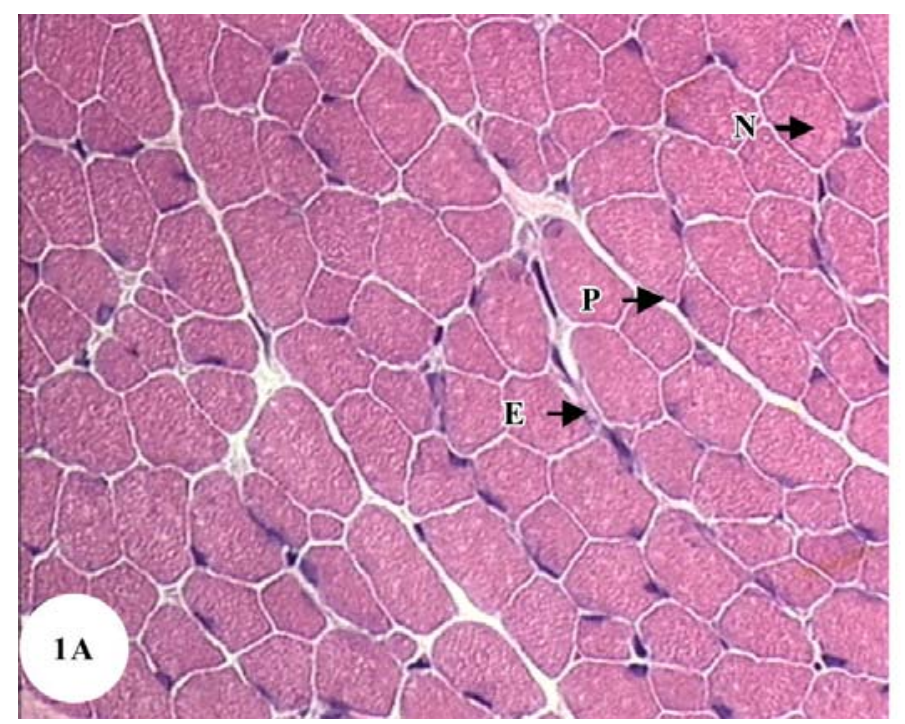

Para contagem das áreas de fibras musculares, foram analisadas dez áreas de 46.562,105 $\mu^{2}$, cada uma correspondente a $0,4654 \mathrm{~cm}^{2}$. Esses mesmos campos microscópicos foram utilizados para mensurações dos diâmetros das fibras. Nesta etapa, utilizou-se o método de mensuração do menor diâmetro da fibra, conforme descrito por Dubowitz \& Brooke (1973). Para obtenção da área do corte transversal do músculo, foi utilizada uma lupa acoplada ao analisador de imagens (Videoplan - OPTIMAS - USA) e a um computador.

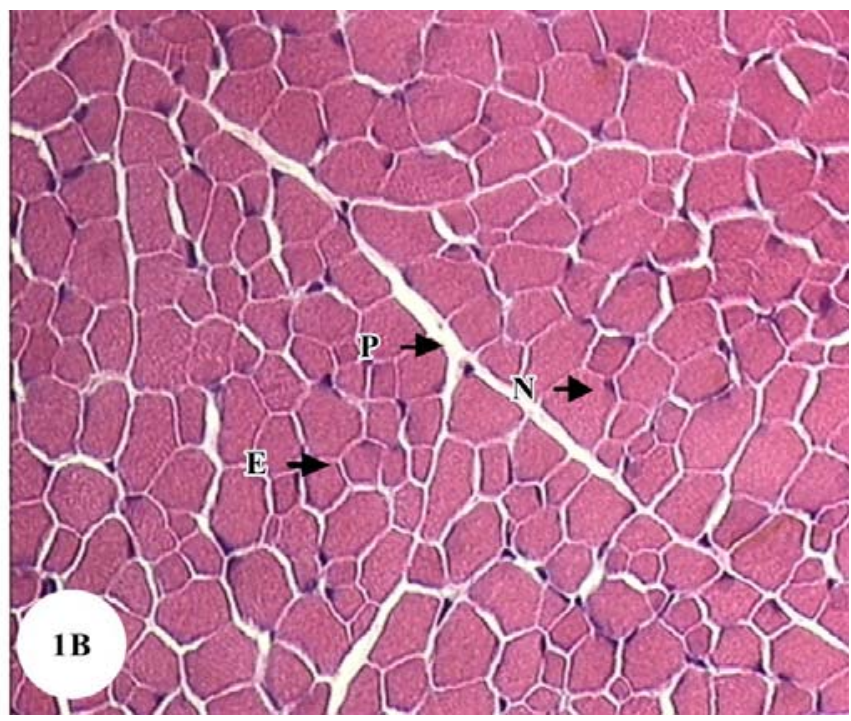

Figura 1 - Cortes transversais do semitendinosus de cordeiros $1 / 2$ Dorper-Santa Inês ao nascimento, endomísio (E), núcleo (N) e perimísio (P). 1A: parto simples; 1B: parto duplo, HE, 200X.

O delineamento utilizado foi inteiramente casualiado e os dados foram analisados pelo Sistema de Análises Estatísticas e Genéticas (SAEG, 1997), procedimento GLM, considerando o nível de significância de 5\% pelo teste Tukey e adotando-se o seguinte modelo:

$$
\mathrm{Y}_{\mathrm{ijklm}}=\mu+\mathrm{TM}_{\mathrm{i}}+\mathrm{TT}_{\mathrm{j}}+\mathrm{TP}_{\mathrm{k}}+\mathrm{TS}_{1}+\mathrm{TM} \times \mathrm{TT}_{\mathrm{ij}}+\mathrm{TM} \times
$$
$\mathrm{TP}_{\mathrm{ik}}+\mathrm{TM} \times \mathrm{TS}_{\mathrm{il}}+\mathrm{TT} \times \mathrm{TP}_{\mathrm{jk}}+\mathrm{TT} \times \mathrm{TS}_{\mathrm{jl}}+\mathrm{TP} \times \mathrm{TS}_{\mathrm{kl}}+\mathrm{e}_{\mathrm{ijk}}$, em que:

$\mathrm{Y}_{\mathrm{ijklm}}=$ observação referente ao animal m, nascido de parto $\mathrm{k}$, terminado com a dieta $\mathrm{j}$, cuja ovelha recebeu na gestação a dieta $\mathrm{i} ; \mu=$ constante geral; $\mathrm{TM}_{\mathrm{i}}=$ efeito do tipo da dieta i na gestação; em que $\mathrm{i}=1,2,3 \mathrm{e} 4 ; \mathrm{TT}_{\mathrm{j}}=$ efeito da dieta de terminação $\mathrm{j}$, sendo $\mathrm{j}=1$ e $2 ; \mathrm{TP}_{\mathrm{k}}=$ efeito do tipo de parto $\mathrm{k}$; sendo $\mathrm{k}=1$ e $2 ; \mathrm{TS}_{1}=$ efeito do tipo de sexo 1 ; sendo $1=1$ e $2 ; \mathrm{TM} \times \mathrm{TT}_{\mathrm{ij}}=$ efeito da interação entre o tratamento materno e dieta de terminação; $\mathrm{TM} \times \mathrm{TP}_{\mathrm{ij}}=$ efeito da interação entre o tratamento materno e tipo de parto; $\mathrm{TM} \times \mathrm{TS}_{\mathrm{ik}}=$ efeito da interação entre o tratamento materno e tipo de sexo; TT $\times \mathrm{TP}_{\mathrm{jk}}=$ efeito da interação entre dieta de terminação e tipo de parto; $\mathrm{TT} \times \mathrm{TS}_{\mathrm{j} 1}=$ efeito da interação entre dieta de terminação e tipo de sexo; $\mathrm{TP} \times \mathrm{TS}_{\mathrm{kl}}=$ efeito da interação entre o tipo de parto e tipo de sexo; $\mathrm{e}_{\mathrm{ijklm}}=$ erro aleatório associado a cada observação $\mathrm{Y}_{\mathrm{ijklm} \text {. }}$.

Foi realizada análise de regressão, utilizando-se os teores de PB das dietas durante a gestação com nível de significância de 5\% pelo teste Tukey.

\section{Resultados e Discussão}

As ovelhas que receberam suplementação proteica na fase inicial de gestação proporcionaram aos cordeiros pesos semelhantes ao nascimento, aos 30 dias e aos 58 dias de idade (Tabela 3). Entre os parâmetros produtivos, o peso ao nascer dos cordeiros é importante, pois está associado à sua sobrevivência, pois cordeiros nascidos com baixo peso têm maior dificuldade em procurar alimento, o que não aconteceu neste trabalho. 
Tabela 3 - Peso e ganho médio diário de cordeiros $1 \frac{1}{2}$ Dorper-Santa Inês de acordo com a suplementação materna, o sexo e o tipo de parto

$\begin{array}{lllll}\text { Peso ao Peso aos } & \text { Peso aos } & \text { Ganho de peso de peso }\end{array}$

nascimento $(\mathrm{kg})$

30 dias $(\mathrm{kg})$

58 dias $(\mathrm{kg})$

diário (0 a 30 dias $)$

diário (0 a 58 dias)

$15,20 \%$ PB

$22,48 \%$ PB

$26,52 \%$ PB

$35,65 \%$ PB

$\begin{array}{lll}\text { Macho } & 5,13 \mathrm{a} \pm 0,13 & 9,86 \pm 2,19 \\ \text { Fêmea } & 4,51 \mathrm{~b} \pm 0,22 & 9,45 \pm 2,31\end{array}$

Simples

Duplo

$5,21 \mathrm{a} \pm 0,11$

$4,30 \mathrm{~b} \pm 0,12$

4,82

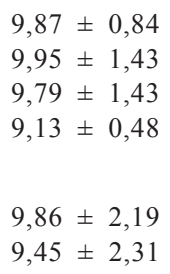

$10,44 \mathrm{a} \pm 0,39$

$8,61 b \pm 0,42$

9,87
Dieta materna

$17,29 \pm 1,51$

$13,94 \pm 2,56$

$16,15 \pm 2,45$

$14,13 \pm 1,45$

Sexo

$16,80 \mathrm{a} \pm 2,07$

$13,95 b \pm 1,34$

Tipo de parto

$17,33 \mathrm{a} \pm 1,60$

$12,72 b \pm 2,04$

15,34
$0,162 \pm 0,01$

$0,165 \pm 0,01$

$0,172 \pm 0,01$

$0,150 \pm 0,01$

$0,157 \pm 0,01$

$0,164 \pm 0,01$

$0,174 \pm 0,01$

$0,143 \pm 0,01$

0,161
$0,201 \pm 0,01$

$0,169 \pm 0,01$

$0,186 \pm 0,01$

$0,166 \pm 0,01$

$0,193 \pm 0,01$

$0,166 \pm 0,01$

$0,204 \mathrm{a} \pm 0,01$

$0,146 \mathrm{~b} \pm 0,01$ 0,179

Médias, dentro de cada classe, seguidas de letras diferentes na coluna, diferem pelo teste Tukey a $5 \%$.

Os maiores pesos ao nascimento e ao desmame nos machos provavelmente foi ocasionado pela fisiologia desses animais, que apresentam maior velocidade de crescimento, maior eficiência alimentar e maior deposição de tecido muscular. Bhasin et al. (2003) atribuem essas características à testosterona e à hipertrofia muscular, que alteram o número de mionúcleos, o número de células somáticas e a massa adiposa. A hipertrofia muscular seria o efeito estimulante da testosterona sobre as célulastronco da linhagem miogênica, inibindo a diferenciação da linhagem adipogênica. Barros et al. (2005), em pesquisa com cordeiros $1 / 2$ Dorper-Santa Inês machos e fêmeas desmamados aos 70 dias de idade, não observaram diferença $(\mathrm{P}>0,05)$ no peso ao nascimento $(4,67$ e $4,50 \mathrm{~kg})$ e ao desmame $(18,16$ e $17,29 \mathrm{~kg})$ entre machos e fêmeas

Os pesos ao nascimento e ao desmame foram influenciados $(\mathrm{P}<0,05)$ pelo sexo e tipo de parto (Figura 2$)$, provavelmente devido à inexistência de competição intrauterina, o que favoreceu os cordeiros nascidos de partos simples. Do nascimento ao desmame, somente o tipo de parto influenciou o ganho de peso dos cordeiros, que foi maior $(\mathrm{P}<0,05)$ nos animais de parto simples, provavelmente em razão da produção de leite da mãe, pois ovelhas, quando parem gêmeos, produzem mais leite, porém não o dobro (Ramsey et al., 1994). Os teores de proteína bruta no terço inicial de gestação provavelmente foram suficientes para suprir as exigências nutricionais das ovelhas nessa fase inicial de gestação, pois, de acordo com Everitt (1967), somente a restrição nutricional severa na fase inicial de gestação pode reduzir o crescimento fetal nos cordeiros.

Zundt et al. (2006), em trabalho com cordeiros Santa Inês, oriundos de ovelhas que receberam suplementação durante a gestação, obtiveram resultados inferiores aos deste experimento, com valores médios para peso ao nascimento de $3,2 \mathrm{~kg}$ e ganho de peso diário ( 0 a 60 dias) de $0,167 \mathrm{~kg} / \mathrm{dia}$. Os resultados inferiores obtidos por esses autores podem estar relacionados à raça, Santa Inês, uma vez que os animais não resultaram de cruzamento com raças especialistas para produção de carne.

Resultados semelhantes aos deste experimento foram obtidos por alguns pesquisadores, como Carneiro et al. (2007), que trabalharam com animais $1 / 2$ Dorper-Santa Inês e encontraram 8,57 e $14,02 \mathrm{~kg}$ aos 30 e 60 dias de idade, respectivamente.

Houve diferença $(\mathrm{P}<0,05)$ entre cordeiros nascidos de parto simples e duplo, com 5,21 e 4,30 kg para peso ao nascimento, 10,44 e 8,61 kg para cordeiros com 30 dias, 17,33 e $12,72 \mathrm{~kg}$ para desmama e 0,204 e $0,146 \mathrm{~kg} /$ dia para o desempenho do nascimento à desmama para parto simples e duplo, respectivamente (Tabela 3). Da mesma forma, Barros et al. (2005) observaram diferença $(P<0,05)$ entre tipo de partos nos pesos ao nascimento $(5,02$ e $4,15 \mathrm{~kg})$ e desmame $(20,49$ e $14,96 \mathrm{~kg})$, respectivamente.

O maior peso ao desmame nos animais nascidos de parto simples pode ser explicado pelo fato de o consumo de leite ser um fator importante para o crescimento dos cordeiros nas primeiras semanas de vida. As ovelhas que parem gêmeos apresentam maior produção de leite, porém, não o dobro do que uma ovelha de parto simples produz. Isso explica o melhor desempenho dos cordeiros de partos simples em relação aos de parto duplo (Ramsey et al., 1994; Silva \& Araújo, 2000).

O ganho de peso diário nos primeiros 28 dias da terminação não diferiu $(\mathrm{P}>0,05)$ entre os sistemas de terminação, possivelmente pelo fato de que cordeiros não apresentaram ganho compensatório, devido ao manejo alimentar anteriormente adotado, que foi ração no creep feeding sem restrição. No período total de terminação 
(Tabela 4), cordeiros nascidos de parto simples apresentaram maior ganho de peso diário $(\mathrm{P}<0,05)$. O maior diâmetro das fibras musculares em animais oriundos de parto simples pode ter ocasionado os melhores ganhos de peso na fase de terminação. Greenwood et al. (2002) observaram que cordeiros Suffolk $\times$ Finnsheep-Dorset nascidos com baixo peso $(2,28 \mathrm{~kg})$ obtiveram ganho de peso diário de $0,150 \mathrm{~kg}$, inferiores aos obtidos pelos cordeiros com alto peso ao nascer $(4,84 \mathrm{~kg})$, que alcançaram ganhos médios diários de $0,337 \mathrm{~kg}$.

O desempenho dos cordeiros na fase de terminação não foi influenciado $(\mathrm{P}>0,05)$ pela suplementação materna $(0,317 \mathrm{~kg} / \mathrm{dia})$ nem pela dieta de terminação $(0,314 \mathrm{~kg} / \mathrm{dia})$. É possível que esse comportamento esteja relacionado à dieta, que foi formulada para obtenção dos mesmos ganhos e ter sido fornecida à vontade durante todo o período

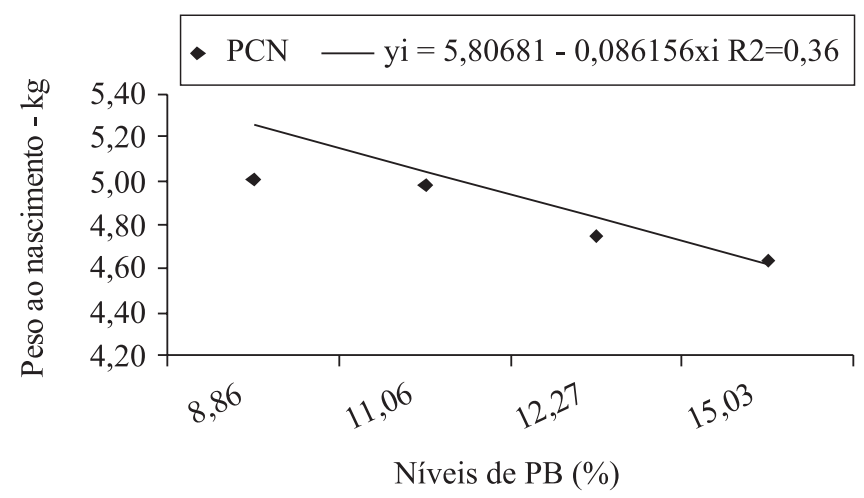

Figura 2 - Regressão do peso ao nascimento (PCN) de cordeiros machos e fêmeas de acordo com suplementação proteica fornecida às mães durante a gestação. experimental. Santello et al. (2006) não observaram efeito $(\mathrm{P}<0,05)$ da suplementação e durante a gestação e da terminação em confinamento ou pastagem + suplementação sobre o ganho de peso $(0,153 \mathrm{~kg} / \mathrm{dia})$ de filhas de cordeiras $1 / 2$ Dorset-Santa Inês.

Animais de parto simples $(0,348 \mathrm{~kg} / \mathrm{dia})$ foram superiores aos de parto duplo $(0,283 \mathrm{~kg} / \mathrm{dia})$ do início da terminação até ao abate (Tabela 5). Carneiro et al. (2007) concluíram que cordeiros $1 / 2$ Dorper-Santa Inês apresentaram maior velocidade de crescimento em comparação a outros grupos genéticos ( $1 / 2$ Dorper - Morada Nova e $1 / 2$ Dorper - RaboLargo) após 30 dias de idade.

Foi observado efeito de interação $(\mathrm{P}<0,05)$ entre sexo e dieta de terminação sobre o ganho de peso diário, uma vez que as respostas diferiram de acordo com o sexo e com a dieta de terminação: no grupo alimentado com a dieta contendo grãos de girassol, o desempenho não apresentou diferenças $(\mathrm{P}>0,05)$ entre machos e fêmeas (Tabela 6). Esse resultado provavelmente está relacionado à maior hipertrofia muscular, ocasionada pelo hormônio testosterona nos animais machos sobre as células-tronco da linhagem miogênica. Barros et al. (2005) não observaram efeito de interação entre sexo e dieta em cordeiros machos $1 \frac{1}{2}$ DorperSanta Inês terminados em confinamento. O maior ganho foi de $0,238 \mathrm{~kg} /$ dia no grupo com ingestão de capim-elefante à vontade e $3,5 \%$ de concentrado.

Os animais de parto simples foram os que apresentaram os melhores resultados na idade de abate, pois atingiram mais rapidamente o peso estipulado para abate se comparados aos animais de parto duplo alimentado com a dieta controle. Esse resultado pode ter sido ocasionado pelo maior peso ao desmame, pela maior oferta de leite da

Tabela 4 - Desempenho de cordeiros $1 / 2$ Dorper-Santa Inês na fase de terminação

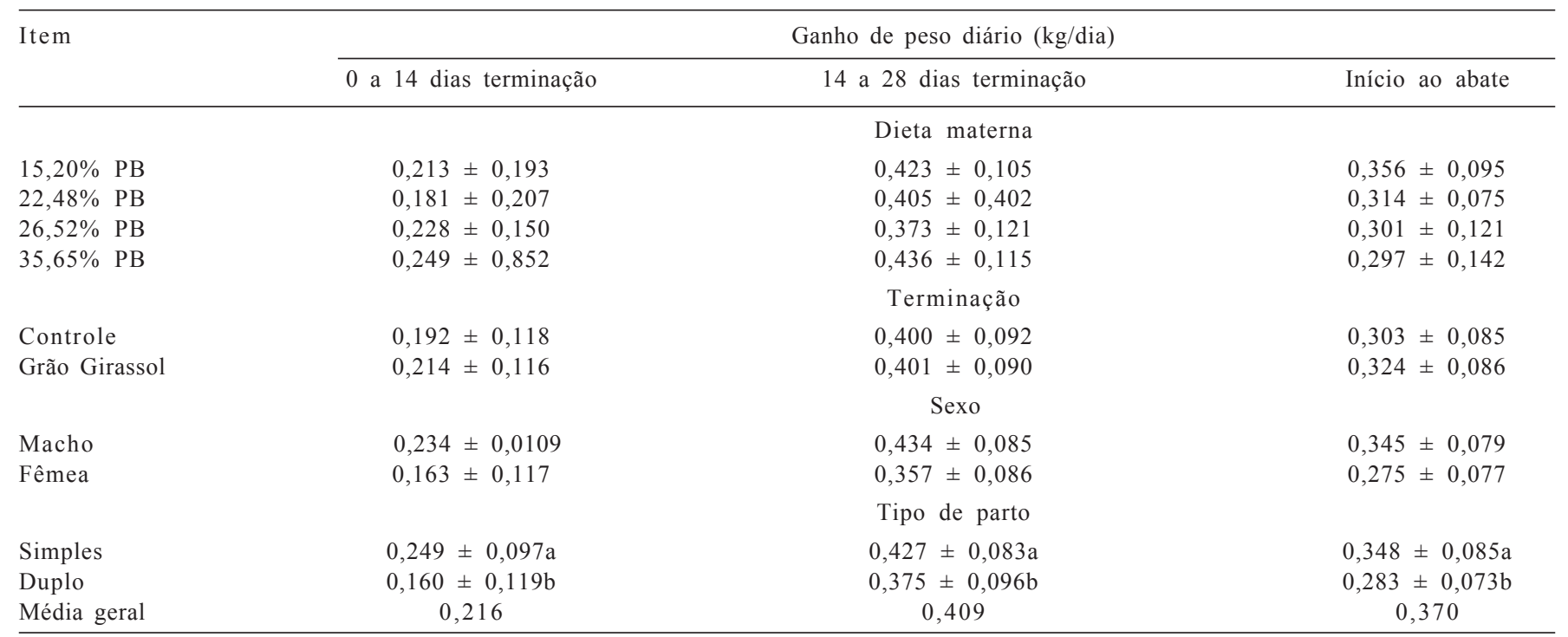

Médias dentro de cada classe seguidas de letras diferentes diferem pelo teste Tukey a 5\%. 
mãe nessa fase que antecede a fase de terminação e também pelo maior diâmetro de fibras musculares esqueléticas, o que pode ter melhorado a taxa de crescimento do animal.

O aumento no nível de proteína na dieta materna reduz o peso dos animais ao nascimento. Do nível mais baixo para o nível mais alto de proteína, ocorreu redução de $0,531 \mathrm{~kg}$ no peso ao nascer.

O crescimento pós-natal do tecido muscular esquelético depende do número e do diâmetro das fibras musculares, que são formadas durante a gestação e pode ser influenciado pelo manejo alimentar das gestantes, afetando assim o crescimento do músculo após o nascimento. Todavia, o diâmetro e número das fibras musculares ao nascimento não diferiram $(\mathrm{P}>0,05)$ entre os níveis de suplementação proteica aplicados às ovelhas. As diferenças no número e diâmetro das fibras musculares estiveram relacionadas $(\mathrm{P}<0,05)$ aos tipos de parto (Tabela 7).

Neste experimento, a suplementação materna não promoveu diferença $(\mathrm{P}>0,05)$ no número nem no diâmetro das fibras musculares ao nascimento, cujas médias foram de 130,82 para o número e $13,16 \mu \mathrm{m}$ de diâmetro, provavelmente pelo fato de não ter havido restrição nutricional na gestação das ovelhas. Segundo Greenwood et al. (2000), esse fato seria observado caso tivesse ocorrido nutrição inadequada na gestação. Houve efeito $(\mathrm{P}<0,05)$ do tipo de parto, pois os cordeiros nascidos de parto duplo apresentaram menor diâmetro de fibras, o que lhes proporcionou maior número de fibras por área analisada (Tabela 6). O oposto ocorreu para os cordeiros nascidos de parto simples e isso pode ter favorecido o maior ganho de peso dos cordeiros de parto simples $(0,204$ vs. $0,146 \mathrm{~kg} /$ dia $)$ de parto duplo (Figuras $1 \mathrm{~A}$ e 1B).

As fibras primárias e secundárias são formadas durante a fase embrionária e fetal, época em que fatores de crescimento e de transcrição interagem, resultando no tecido muscular. Antes da migração para os locais onde serão formados os membros, as células precursoras musculares não são capazes de expressar proteínas da família MyoD, descoberta em 1987, que é um fator de transcrição,

Tabela 5 - Ganho de peso médio diário ( $\mathrm{kg} / \mathrm{dia})$ de cordeiros $1 / 2$ Dorper-Santa Inês de acordo com dieta de terminação e o sexo

\begin{tabular}{lcc}
\hline Sexo & \multicolumn{2}{c}{ Dieta de terminação } \\
\cline { 2 - 3 } & Controle $(\mathrm{kg} /$ dia $)$ & Grãos de girassol $(\mathrm{kg} / \mathrm{dia})$ \\
\hline Macho & $0,384 \mathrm{aA}$ & $0,351 \mathrm{aA}$ \\
Fêmea & $0,258 \mathrm{bA}$ & $0,293 \mathrm{aA}$
\end{tabular}

Médias seguidas de letras minúsculas diferentes nas colunas diferem $(\mathrm{P}<0,05)$ pelo teste Tukey.

Médias seguidas de letras maiúsculas diferentes nas linhas diferem $(\mathrm{P}<0,05)$ pelo teste Tukey. pertencente à família de proteínas "basic helixloop-helix", que controla a diferenciação de células da linhagem miogênica (Cornelison et al., 2000). Animais oriundos de parto simples apresentaram menor número de fibras musculares esqueléticas, porém com maior diâmetro, o que provavelmente promoveu maior ganho médio diário. $\mathrm{Na}$ fase uterina, quando ocorre a formação das fibras musculares esqueléticas, os cordeiros de parto simples podem ter tido aporte maior de nutrientes, em decorrência da nãocompetição intrauterina. Toda essa sequência de reações pode ser influenciada pela nutrição das ovelhas nesta fase, assim, o crescimento muscular dos cordeiros depende do número e diâmetro das fibras musculares, porém, pesquisas recentes comprovam necessidade de quantificar também o DNA das fibras musculares.

Greenwood et al. (2000), em pesquisa com cordeiros com alto $(4,84 \mathrm{~kg})$ e baixo $(2,28 \mathrm{~kg})$ peso ao nascimento, verificaram que o peso ao nascer teve pouco efeito sobre o desenvolvimento muscular dos cordeiros até ao abate, aos $20 \mathrm{~kg}$ de peso vivo. Esses autores atribuíram esse fato à quantidade de DNA no músculo, e não ao número de fibras musculares.

Este experimento foi realizado somente com a contagem do número e diâmetro das fibras musculares, ou seja, não foi realizada a quantificação de DNA. Beermann et al. (1983)

Tabela 6 - Médias de idade ao abate de cordeiros $1 \frac{1}{2}$ Dorper-Santa Inês para dieta de terminação com o tipo de parto

\begin{tabular}{lccc}
\hline & \multicolumn{3}{c}{ Dieta de terminação } \\
\cline { 2 - 4 } Tipo de parto & Controle & Grão de girassol & Média geral \\
\hline Simples & $87,80 \mathrm{aA}$ & $102,64 \mathrm{aB}$ & 98,00 \\
Duplo & $102,64 \mathrm{bA}$ & $113,66 \mathrm{aA}$ & 112,50 \\
Média geral & 99,80 & 105,00 & \\
\hline
\end{tabular}

Médias seguidas de letras minúsculas diferentes nas colunas diferem $(\mathrm{P}<0,05)$ pelo teste Tukey.

Médias seguidas de letras maiúsculas diferentes nas linhas diferem $(\mathrm{P}<0,05)$ pelo teste Tukey.

Tabela 7 - Desenvolvimento do músculo semitendinosus de cordeiros $1 / 2$ Dorper-Santa Inês ao nascimento

\begin{tabular}{lcc}
\hline & Número de fibras ${ }^{1}$ & $\begin{array}{c}\text { Diâmetro de fibras } \\
(\mu \mathrm{m})\end{array}$ \\
\hline & \multicolumn{2}{c}{ Dieta materna } \\
$15,20 \%$ PB & $3118,78 \pm 641,26$ & $13,53 \pm 1,13$ \\
$22,48 \%$ PB & $3043,86 \pm 473,62$ & $11,85 \pm 0,91$ \\
$26,52 \%$ PB & $3043,86 \pm 281,22$ & $13,48 \pm 0,68$ \\
$35,65 \%$ PB & $2647,23 \pm 475,68$ & $13,32 \pm 1,39$ \\
& $2347,40 \mathrm{~b} \pm 203,46$ & $14,27 \mathrm{a} \pm 0,58$ \\
Simples & $3490,20 \mathrm{a} \pm 389,97$ & $11,65 \mathrm{~b} \pm 0,60$ \\
Duplo & 2813,45 & 13,16 \\
Média geral & \multicolumn{2}{c}{ parto }
\end{tabular}

Médias seguidas de letras diferentes na coluna diferem pelo teste Tukey a 5\%.

${ }^{1} \mathrm{O}$ número de fibras corresponde a área de $10 \mathrm{~cm}^{2}$. 
relataram a importância do número de mionúcleos, relacionada ao DNA no músculo, ao invés do número de fibras, para melhor desenvolvimento muscular. A restrição nutricional severa na gestação reduz a circulação do hormônio IGF-I, ocasionando, principalmente em cordeiros, baixo peso ao nascimento. A diminuição da expressão do mRNA durante a fase final de gestação provoca retardamento no crescimento fetal de cordeiros (Rhoads et al., 2000). Os hormônios IGF (insulin-like growth factor) são proteínas importantes no controle do metabolismo da insulina, além de regularem a regeneração muscular, pois os IGF-I e IGFII estimulam a proliferação e a diferenciação de células somáticas in vitro (Hawke \& Garry, 2001).

Peinado et al. (2004), em trabalho com cordeiros Segureña, observaram menores valores para o diâmetro das fibras do músculo longissimus thoracis ao nascimento (7,55 $\mu \mathrm{m})$. Entretanto, Zundt (2004) também não observou diferença $(\mathrm{P}>0,05)$ quando as ovelhas receberam suplementação diferenciada nos três períodos da gestação, sendo, 17,52 $\mu \mathrm{m}$ ao nascimento no músculo semitendinosus de cordeiros, 18,11 e 17,29 $\mu$ m para cordeiros nascidos de parto simples e duplo, respectivamente. Mexia et al. (2006) também não notaram diferença $(\mathrm{P}>0,05)$ no diâmetro das fibras musculares entre os tratamentos maternos, que foi suplementação no terço inicial, médio e final de gestação $(11,07 ; 13,11$ e $11,20 \mu \mathrm{m})$. Esses autores também não observaram diferença $(\mathrm{P}>0,05)$ no número de fibras musculares no músculo semitendinosus ao nascimento.

\section{Conclusões}

O suplemento com $15,20 \%$ de $\mathrm{PB}$ em pastagem de capimaruana com $6,2 \%$ de PB na fase inicial de gestação promove maior peso ao nascimento dos cordeiros, porém não influencia no número de fibras musculares. Cordeiros de partos simples apresentam o melhor desempenho do nascimento até ao abate.

\section{Referências}

BARROS, N.N.; VASCONCELO, V.R.; WANDER, A.E. et al. Eficiência bioeconômica de cordeiros F1 Dorper x Santa Inês para produção de carne. Pesquisa Agropecuária Brasileira, v.40, n.8, p.825-831, 2005.

BEERMANN, D.H.; HOOD, L.F.; LIBOFF, M. Satellite cell and myonuclei populations in rat soleus and xtensor digitorum longus muscles after maternal nutritional deprivation and realimentation. Journal of Animal Science, v.57, p.1618-1625, 1983.

BHASIN, S.; TAYLOR, W.E.; SINGH, R. et al. The mechanisms of androgen effects on body composition: mesenchymal pluripotent cell as the target of androgen action. Journal of Gerontology: Biological Sciences, v.58, n.12, p.1103-1110, 2003.
CARNEIRO, P.L.S.; MALHADO, C.H.M.; SOUZA JR., A.A.O. et al Desenvolvimento ponderal e diversidade fenotípica entre cruzamentos de ovinos Dorper com raças locais. Pesquisa Agropecuária Brasileira, v.42, n.7, p.991-998, 2007.

CORNELISON, D.D.; OLWIN, B.B.; RUDNICKI, M.A. et al. Satellite cells in single-fiber culture are differentiation defective and MRF4 deficient. Developmental Biology, v.24, n.2, p.122-137, 2000 .

DUBOWITZ, V.; BROOKE, M.H. Muscle biopsy: a modern approach. Saunders, 1973. 220p.

EVERITT, G.C. Residual effects of prenatal nutrition on the postnatal performance of merino sheep. Proceeding The New Zealand Plant Protection Society, v.27, p.52-68, 1967.

FIGUEIRÓ, P.R.P.; BENAVIDES, M.V. Produção de carne ovina. In: REUNIÃO ANUAL DA SOCIEDADE BRASILEIRA DE ZOOTECNIA, 27., 1990, Campinas. Anais... Campinas: Unicamp, 1990. p.15-31.

FINKELSTEIN, D.L.; ANDRIANAKIS, P.; LUFF, A.R. et al. Development changes in hind limb muscles and diaphragm of sheep. American Journal. Physiology, v.263, p.900-908, 1992.

FOOD AND AGRICULTURE ORGANIZATION (FAO). Disponível em $<$ http://apps.fao.org $>$. Acesso em 7/7/2007.

GREENWOOD, P.L.; HUNT, A.S.; HERMANSON, J.W. et al. Effects of birth weight and postnatal nutrition on neonatal sheep: I. Body growth and composition, and some aspects of energetic efficiency. Journal of Animal Science, v.76, p.2354-2367, 1998.

GREENWOOD, P.L.; HUNT, A.S.; HERMANSON, J.W. et al. Effects of birth weight ans post natal nutrition on neonatal sheep. II. Skeletal muscle growth and development. Journal of Animal Science, n.78, p.50-61, 2000.

GREENWOOD, P.L.; HUNT, A.S.; SLEPETIS, R.M. et al. Effects of birth weight and postnatal nutrition on neonatal sheep: III. Regulation of energy metabolism. Journal of Animal Science, v.80, p.2850-2861, 2002.

HAWKE, T.J.; GARRY, D.J. Myogenic satellite cells: physiology to molecular biology. Journal of Applied Physiology, v.9, n.2, p.534-551, 2001.

KHAN, M.A. The histoenzymology of striated muscle fibres an overview. Cellular Molecular Biology, v.22, p.383-93, 1977.

LILLIE, R.D. Histopathologe technic and pratical histochemistry. 2.ed. New York: Blakiston, 1954. 501p.

LOURENÇO, F.J. Utilização de diferentes métodos para detecção do comportamento endoparasitário em fêmeas ovinas de diferentes grupos raciais. 2006. 63f. Dissertação (Mestrado em Zootecnia) - Universidade Estadual de Maringá, Maringá.

MAIER, A.J.C.; McEWAN, K.G.; DODDS, D.A. et al. Myosin heavy chain composition of single fibers and their origins and distribution in developing fascicles of sheep tibialis cranialis muscles. Journal Muscle Research Cellular Motility, v.13, p.551-572, 1992.

MEXIA, A.A.; MACEDO, F.A.F.; MACEDO, R.M.G. et al. Desempenho e características das fibras musculares esqueléticas de cordeiros nascidos de ovelhas que receberam suplementação alimentar em diferentes períodos da gestação. Revista Brasileira de Zootecnia, v.35, n.4, p.1780-1787, 2006.

NATIONAL RESEARCH COUNCIL - NRC. Nutrients requirements of sheep. Washington: National Academy Press, 1985. 99p.

PEINADO, B.; LATORRE, R.; VÁQUEZ-AUTÓN, J.M.; et al. Histochemical skeletal muscle fibre types in the sheep. Journal of Veterinary Medicine, v.33, p.236-243, 2004.

PULLEN, A.H. The distribution and relative size of fiber type in the extensor digitorum longus and soleus muscles of the adult rat. Journal of Anatomy, v.123, p.467-486, 1977.

RAMSEY, W.S.; HATFIELD, P.G.; WALLACE, J.D. et al. Relationships among ewe milk production and ewe and lamb forage intake in Targhee ewes nursing single or twin lambs. Journal of Animal Science, n.72, p.811-816, 1994. 
RHOADS, R.P.; GREENWOOD, P.L.; BELL, A.W. et al. Nutritional regulation of the genes encoding the acid-labile subunit and other components of the circulating insulin-like growth factor system in the sheep. Journal of Animal Science, v.78, p.2681-2689, 2000 .

SANTELLO, G.A.; MACEDO, F.A.F.; MEXIA, A.A. et al. Características de carcaça e análise do custo de sistemas de produção de cordeiras 1/2 Dorset Santa Inês. Revista Brasileira de Zootecnia, v.35, n.4, p.1852-1859, 2006.

SILVA, F.L.R.; ARAÚJO, A.M. Características de reprodução e de crescimento de ovinos mestiços Santa Inês, no Ceará. Revista Brasileira de Zootecnia, v.29, p.1712-1720, 2000.

SWATLAND, H.J.; CASSENS, R.G. Inhibition of muscle growth in fetal sheep. Journal of Animal Science, v.80, p.503-509, 1973.

UNDERSANDER, D.J.; HOWARD, W.T.; SHAVER, R.D. Milk per acre spreadsheet for combining yeld and quality into a single term. Journal of Production Agriculture, v.6, n.2, p.231-235, 1993.
UNIVERSIDADE FEDERAL DE VICCOSA - UFV. SAEG - Sistema de análises estatísticas e genéticas. Versão 7.1. Viçosa, MG: 1997. 150p.

WILSON, S.J.; McEWAN, J.C.; SHEARD, P.W. et al. Early stages of myogenesis in a large mammal: formation of successive generations of myotubes in sheep tibialis cranialis muscle. Journal Muscle Research, v.13, n.5, p.535-550, 1992.

ZUNDT, M. Desempenho e características de carcaça de cordeiros Santa Inês, filhos de ovelhas suplementadas em diferentes fases da gestação, terminados em confinamento. 2004. 89f. Tese (Doutorado em Zootecnia) Universidade Estadual de Maringá, Maringá.

ZUNDT, M.; MACEDO, FAF.; ASTOLPHI, J.L.L. et al. Desempenho e características de carcaça de cordeiros Santa Inês confinados, filhos de ovelhas submetidas à suplementação alimentar durante a gestação. Revista Brasileira de Zootecnia, v.35, n.3, p.928-935, 2006. 